\title{
ANALYSIS OF COMPOSITE STEEL TUBE INFILLED WITH LEIGHT WEIGHT CONCRETE AND SELF COMPACTING CONCRETE USING ANSYS-14.0
}

\author{
Vijay Kumar H. S ${ }^{1}$, E.Ramesh Babu ${ }^{2}$, N. S Kumar ${ }^{3}$ \\ ${ }^{I}$ Final Year Student, Department of Civil Engineering, Ghousia college of Engineering, Karnataka, India \\ ${ }^{2}$ Associate Professor, Department of Civil Engineering, Ghousia college of Engineering, Karnataka, India \\ ${ }^{3}$ Professor and Director [R\&D-Civil Engineering], Department of Civil Engineering, Ghousia College of \\ Engineering, Karnataka, India
}

\begin{abstract}
To know the clear knowledge about self compacting concrete and light weight concrete when Infilled with composite steel tube and behavior take place after loading on both the Infilled concrete using non linear method by ansys software. The results, that obtained the difference in self compacting and light weight concrete says M20, M30, M40 are testing for ultimate of load capacity is published in this paper. Steel tube is comparing of different dimension of cross section of diameter, thickness' and length. This is the paper focused on the Infilled concrete filled with steel tube.
\end{abstract}

Keywords: CFST, Light Weight Concrete, Self Compacting Concrete, Hollow Steel Tube, Ansys-14

\section{INTRODUCTION}

Concrete Infilled steel tube column members utilized the both the concrete and steel. They are comprised of a hollow steel section of the circular Infilled with a plain concrete of mixture. This are broadly using in a large-rises building or tall structure as beam-column and columns, and as beams in small-rise building where an efficient structural systems is a required for better. There is many different advantageous relations to the such a structural system in both wise of structural performed and the constructions context. The local buckling problems related to thinned-wall structure of steel tubes are restricted due to the appearing of the core of concrete. Further, they performed when there is concrete infilled is improvised due to confined effectively exerting by steel member. The distributions of the material in cross sections make the systems very efficiently in the term of which its structurally performed. Then steel lying in the circumstance of concrete material where it performed most effectively in tensile and flexure.

\section{CLASSIFICATION OF CFT MEMBERS}

There are several or different types of column Infilled steel tube as shown in figure:

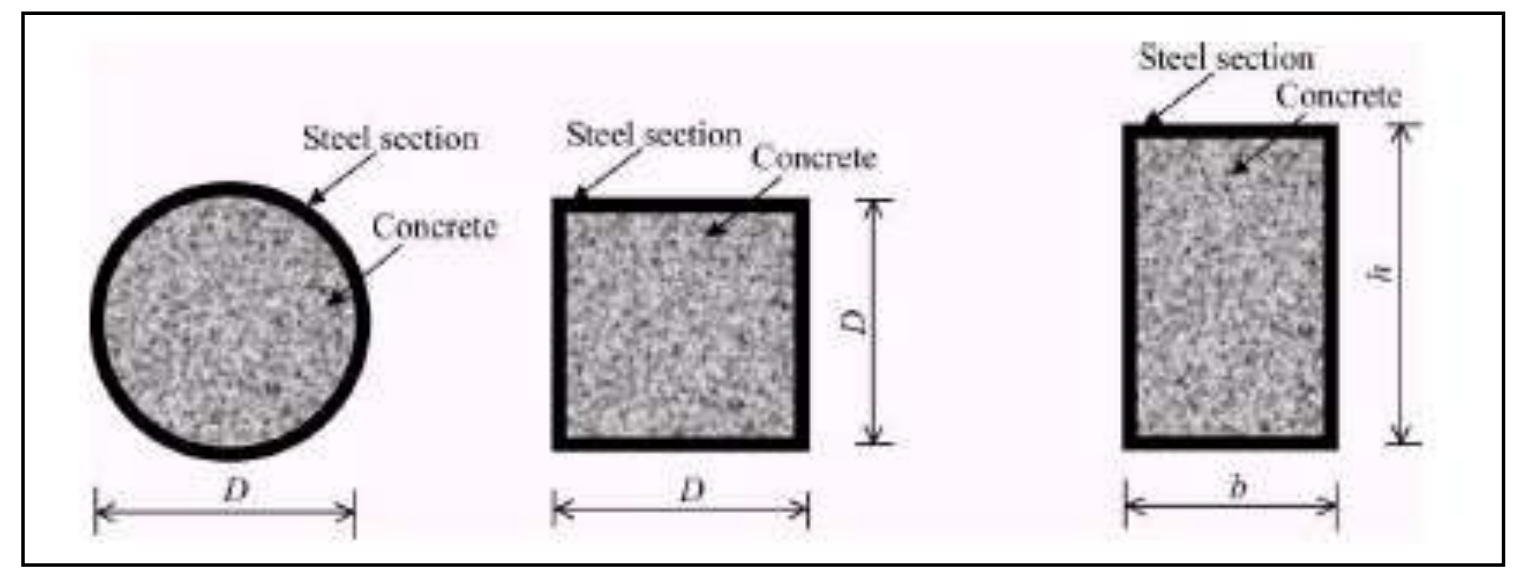

Fig 1 a) circular b) square c) rectangular 


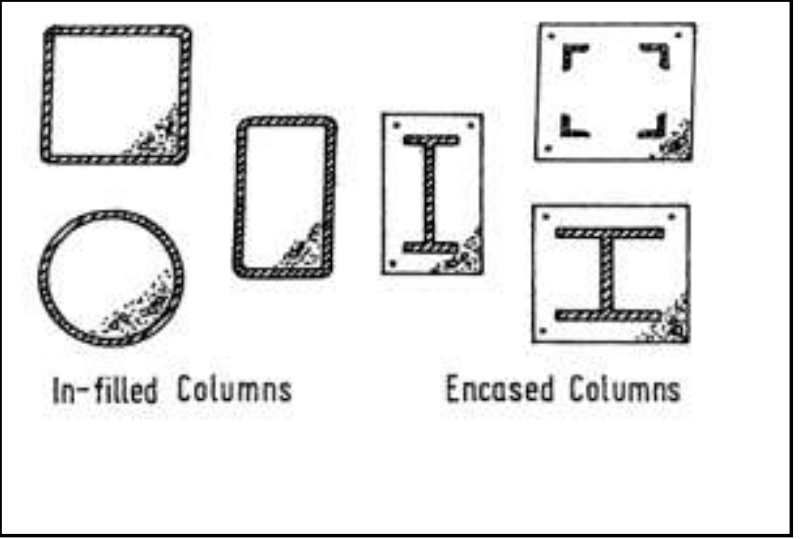

Fig 2 a) Infilled columns b) Encased columns

\section{ADVANTAGES OF CFT USING ENCASED COLUMNS}

Composite columns combined the advantage of the both a concrete \& steels, such as the speed of strength, construction, \& light weight steel, \& mass, damping, stiffness, \& economic of concrete. The steel column served as a straight frame to complete the constructions of remaining of the structures. Thus for ductility improving. Prolong concluding that concrete Infilled delayed the global buckling of steel tubes. However, not increased in material strength of concrete due to the confined of steel tubes was taken in to account.

\section{FINITE ELEMENT ANALYSIS (FEA)}

FEA modeling is the analysis is conducted in ANSYS workbench modules [14.0], where material nonlinear is considered. Material modeling: Elastic-plastic model is utilized to describe a clear constitutive behavior of steels and multi-linear of the concrete \& Bilinear properties for steel tube used. The modulus of elasticity of concrete is taken as $\sqrt{ } 4700$ according to the code IS 456:2000, where fck is compressive characteristic strength of concrete.

\section{MATERIAL SPECIFICATIONS}

The material properties are listed below.

\section{STEEL}

Material: - Steel Fe 310Mpa

Young's Modulus E=200×10^9pa

Poison ratio $\mathrm{v}=0.3$

Density $\mathrm{p}=78 \mathrm{KN} / \mathrm{m} 3$

\section{CONCRETE}

\section{SELF COMPACTING CONCRETE (SCC)}

Grade of Concrete: M20, M30, M40

Young's Modulus E=22360.7Mpa

Young's Modulus E $=27386.12 \mathrm{Mpa}$

Young's Modulus E $=31622.78 \mathrm{Mpa}$

Poison's ratio $\mathrm{v}=0.16-0.3$

Density $\mathrm{p}=2400 \mathrm{~kg} / \mathrm{m}$

\section{LIGHT WEIGHT CONCRETE (LWC)}

Grade of concrete $=$ M20, M30, M40

$\mathrm{E}=22360.70 \mathrm{Mpa}$

$\mathrm{E}=27386.12 \mathrm{Mpa}$

$\mathrm{E}=31622.78 \mathrm{Mpa}$

Poison ratio $\mathrm{v}=0.2$

Density $\mathrm{p}=1850 \mathrm{~kg} / \mathrm{m}$

\section{BREIF DESCRIBE OF SOFTWARE'S USED}

The following are the software's tools used below are;

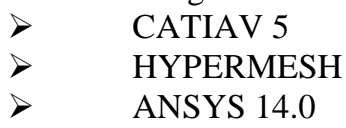

\section{CATIA V5}

CATIA software also used to design the geometry that is modeling this software gives more accurate 3 -d modeling. Catia is the present software used for developmenting solution for all manufactured catiav5 using in the processing of the buildings the globe leading facilities for new research.

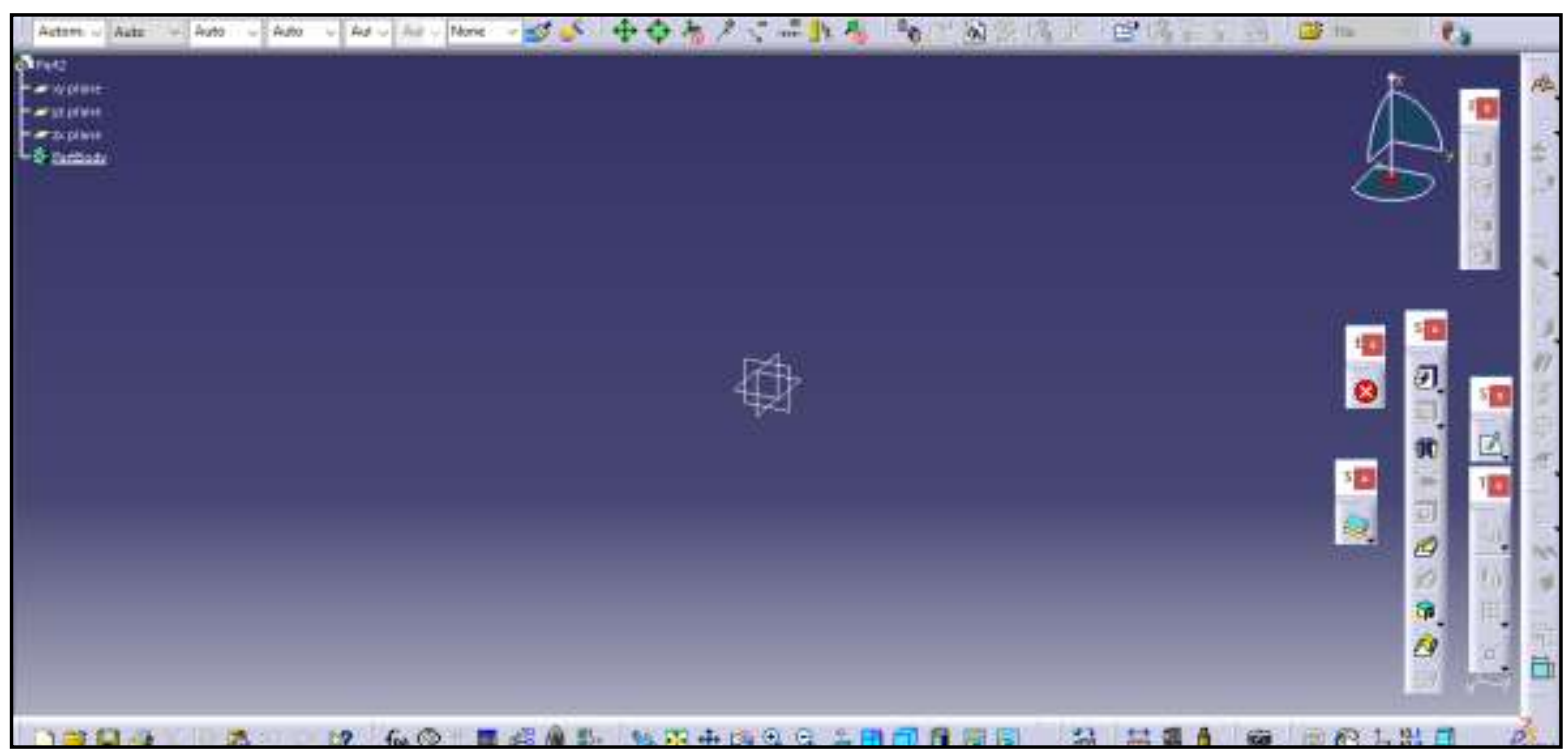

Fig 3 Main menus of CATIA V5 


\section{Hypermesh}

HYPERMESH; - HY performance and therefore it is a performance finite element pre and post processer. Used for modeling the specimen and also for the purpose of analysis stands for high and per stands for performance and therefore it is a high

\section{Flow Chart of the FEM Process}

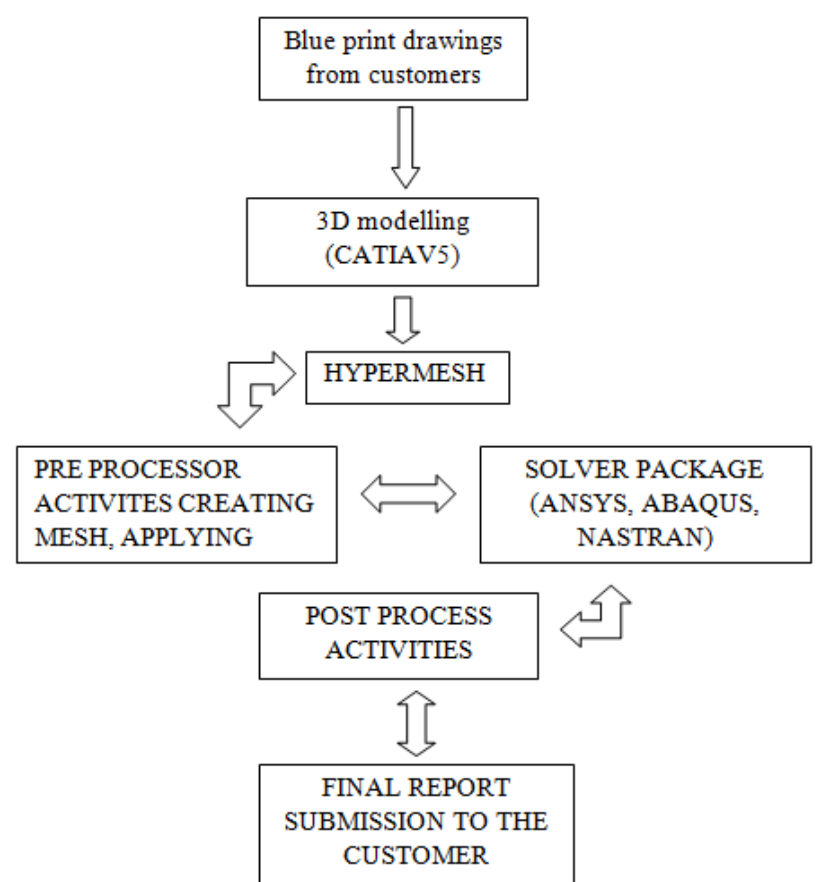

Fig 4 flowchart of hyper mesh

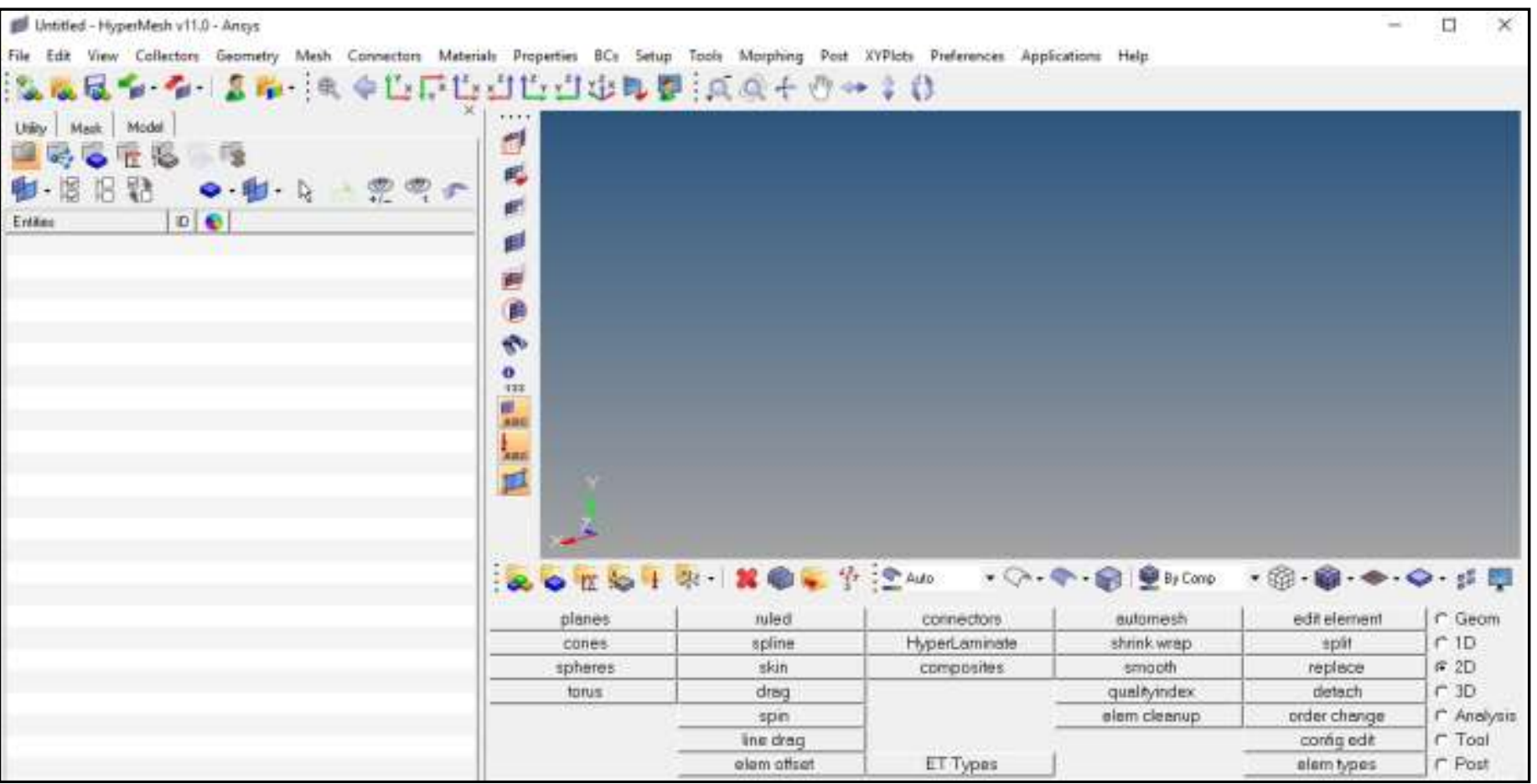

Fig 5 Main menu's of hyper mesh

\section{Analysis}

Finite Element Method

- For many of the technical engineering problem of analytical solution are not better suitable, because of the complexity of the material properties, grades, for different boundary conditions and the structure itself.

- Finite element method (FEM) is the represents of the structure by an assemblage of the subdivisions called finite element.

\begin{abstract}
ANSYS
ANSYS is one of the commercial packages of FEM software having the capable of ranged from the simple, nonlinear, statical analysis to complex transient dynamic, nonlinear analysis. It will be available only in the module. Each modules is applicable for the specific problem. However, subsequently ansys: is the CFD package tool applicable for Fluid Flows. The advantages of the Ansys package comparing with different others competitive software is its available as bundle of software's of post Processor.
\end{abstract}




\section{Modelling}

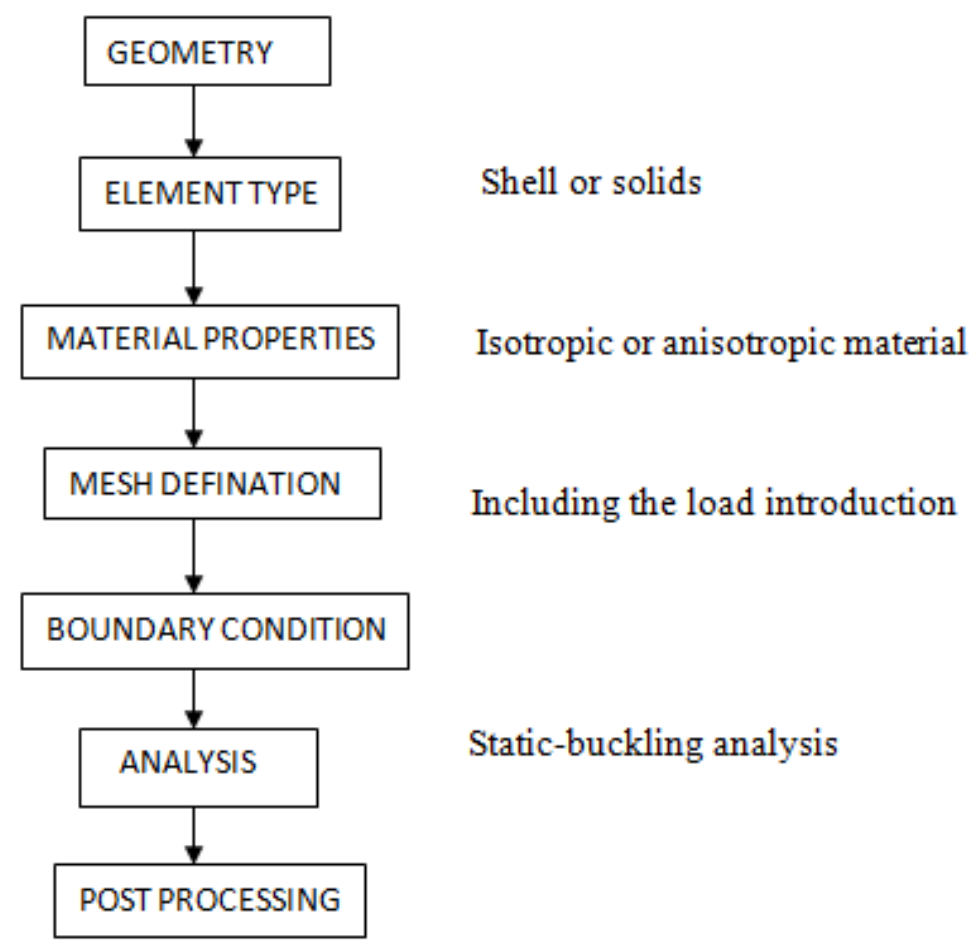

Fig 6 MODELLING PROCEURE

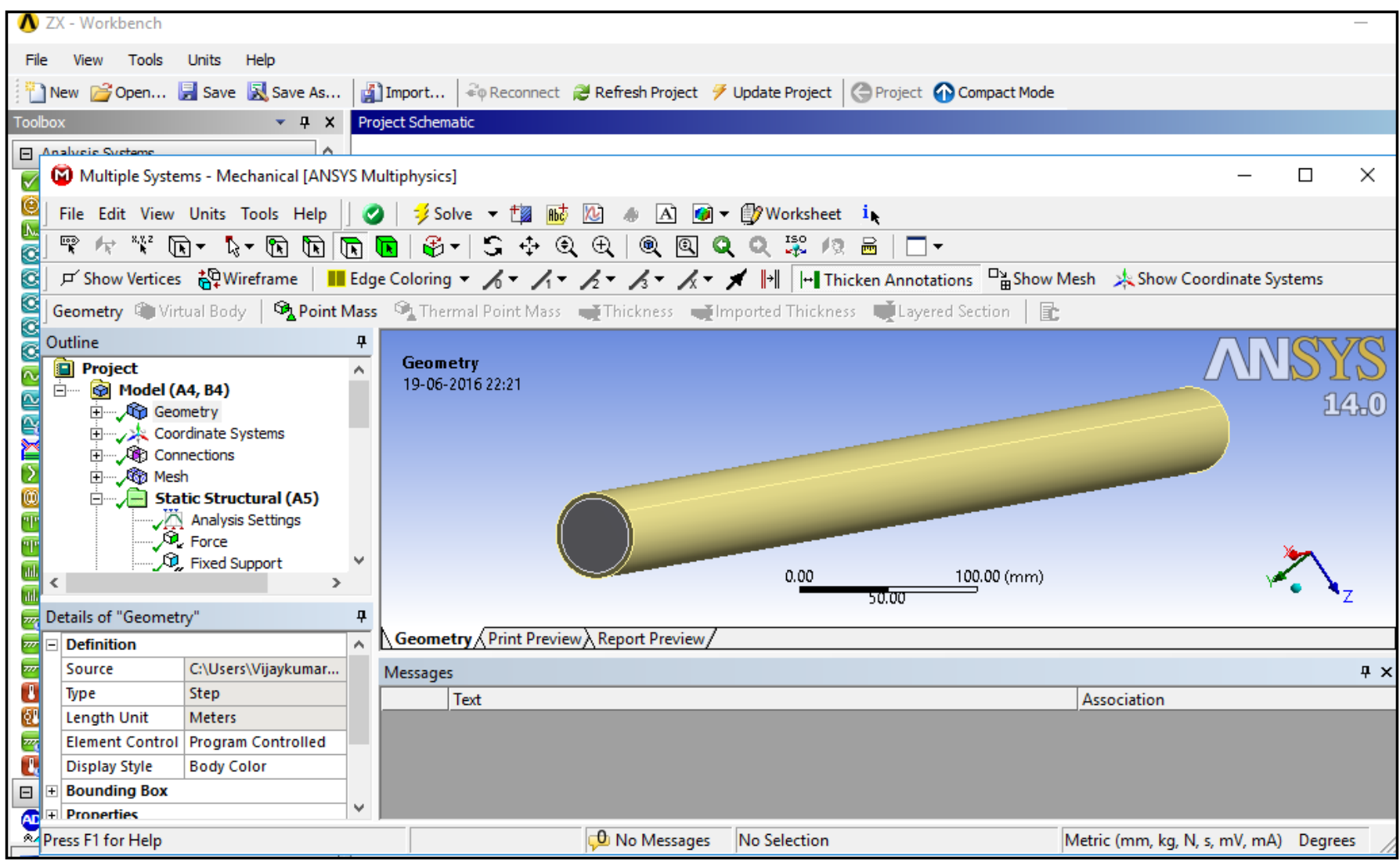

Fig 7 modeling in ansys

Ansys is used to selecting different types of various element. This will be providing one-Dimensional element (beam element) two-Dimensional element (shell element) and three-Dimensional element (solid elements) were found to be more efficiency in modeling of both concrete and steel tube structure because it gives good better masses. 
7. DIMENSIONS OF CIRCULAR COLUMN AS PER L/D RATIO FOLLOWED.

Table 1:- DIMENSIONS OF CIRCULAR COLUMNS

(a) $\mathrm{L} / \mathrm{D}$ ratio for $6,12,16$

\begin{tabular}{|c|c|c|c|c|c|}
\hline$\frac{\sqrt{1}}{\frac{2}{0}}$ & 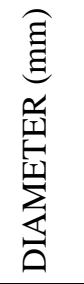 & $\begin{array}{l}\underset{\Xi}{\Xi} \\
\underset{\hat{\Xi}}{E}\end{array}$ & $\underset{\Xi}{\ominus}$ & 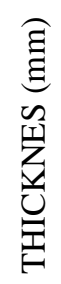 & 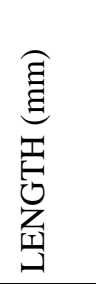 \\
\hline \multirow{9}{*}{ 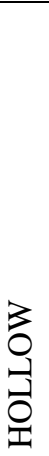 } & \multirow{3}{*}{33.7} & \multirow{3}{*}{10.5} & 6 & 3.2 & 202.2 \\
\hline & & & 12 & 3.2 & 404.4 \\
\hline & & & 16 & 3.2 & 539.2 \\
\hline & \multirow{3}{*}{42.2} & \multirow{3}{*}{13.3} & 6 & 3.2 & 254.4 \\
\hline & & & 12 & 3.2 & 508.8 \\
\hline & & & 16 & 3.2 & 678.4 \\
\hline & \multirow{3}{*}{48.8} & \multirow{3}{*}{15.1} & 6 & 3.2 & 289.8 \\
\hline & & & 12 & 3.2 & 579.6 \\
\hline & & & 16 & 3.2 & 772.8 \\
\hline \multirow{9}{*}{ 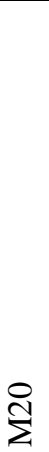 } & \multirow{3}{*}{33.7} & \multirow{3}{*}{10.5} & 6 & 3.2 & 202.2 \\
\hline & & & 12 & 3.2 & 404.4 \\
\hline & & & 16 & 3.2 & 539.2 \\
\hline & \multirow{3}{*}{42.2} & \multirow{3}{*}{13.3} & 6 & 3.2 & 254.4 \\
\hline & & & 12 & 3.2 & 508.8 \\
\hline & & & 16 & 3.2 & 678.4 \\
\hline & \multirow{3}{*}{48.8} & \multirow{3}{*}{15.1} & 6 & 3.2 & 289.8 \\
\hline & & & 12 & 3.2 & 579.6 \\
\hline & & & 16 & 3.2 & 772.8 \\
\hline \multirow{9}{*}{ 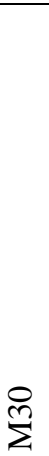 } & \multirow{3}{*}{33.7} & \multirow{3}{*}{10.5} & 6 & 3.2 & 202.2 \\
\hline & & & 12 & 3.2 & 404.4 \\
\hline & & & 16 & 3.2 & 539.2 \\
\hline & \multirow{3}{*}{42.2} & \multirow{3}{*}{13.3} & 6 & 3.2 & 254.4 \\
\hline & & & 12 & 3.2 & 508.8 \\
\hline & & & 16 & 3.2 & 678.4 \\
\hline & \multirow{3}{*}{48.8} & \multirow{3}{*}{15.1} & 6 & 3.2 & 289.8 \\
\hline & & & 12 & 3.2 & 579.6 \\
\hline & & & 16 & 3.2 & 772.8 \\
\hline \multirow{9}{*}{$\stackrel{゚}{\dot{\perp}}$} & \multirow{3}{*}{33.7} & \multirow{3}{*}{10.5} & 6 & 3.2 & 202.2 \\
\hline & & & 12 & 3.2 & 404.4 \\
\hline & & & 16 & 3.2 & 539.2 \\
\hline & \multirow{3}{*}{42.2} & \multirow{3}{*}{13.3} & 6 & 3.2 & 254.4 \\
\hline & & & 12 & 3.2 & 508.8 \\
\hline & & & 16 & 3.2 & 678.4 \\
\hline & \multirow{3}{*}{48.8} & \multirow{3}{*}{15.1} & 6 & 3.2 & 289.8 \\
\hline & & & 12 & 3.2 & 579.6 \\
\hline & & & 16 & 3.2 & 772.8 \\
\hline
\end{tabular}

(b) $\mathrm{L} / \mathrm{D}$ ratio for $8,10,12$

\begin{tabular}{|c|c|c|c|c|c|}
\hline$\frac{\sqrt{0}}{\stackrel{\Delta}{0}}$ & 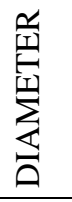 & $\stackrel{5}{\circ}$ & 9 & 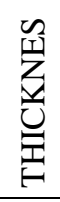 & 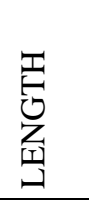 \\
\hline \multirow{9}{*}{ 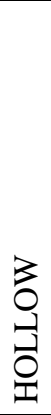 } & \multirow{3}{*}{33.7} & \multirow{3}{*}{10.5} & 8 & 3.2 & 269.6 \\
\hline & & & 10 & 3.2 & 337 \\
\hline & & & 14 & 3.2 & 471.8 \\
\hline & \multirow{3}{*}{42.2} & \multirow{3}{*}{13.3} & 8 & 3.2 & 339.2 \\
\hline & & & 10 & 3.2 & 424 \\
\hline & & & 14 & 3.2 & 594.6 \\
\hline & \multirow{3}{*}{48.8} & \multirow{3}{*}{15.1} & 8 & 3.2 & 386.4 \\
\hline & & & 10 & 3.2 & 483 \\
\hline & & & 14 & 3.2 & 676.2 \\
\hline \multirow{9}{*}{ 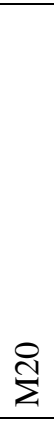 } & \multirow{3}{*}{33.7} & \multirow{3}{*}{10.5} & 8 & 3.2 & 269.6 \\
\hline & & & 10 & 3.2 & 337 \\
\hline & & & 14 & 3.2 & 471.8 \\
\hline & \multirow{3}{*}{42.2} & \multirow{3}{*}{13.3} & 8 & 3.2 & 339.2 \\
\hline & & & 10 & 3.2 & 424 \\
\hline & & & 14 & 3.2 & 594.6 \\
\hline & \multirow{3}{*}{48.8} & \multirow{3}{*}{15.1} & 8 & 3.2 & 386.4 \\
\hline & & & 10 & 3.2 & 483 \\
\hline & & & 14 & 3.2 & 676.2 \\
\hline \multirow{9}{*}{ 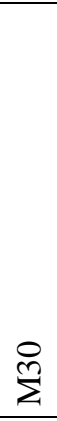 } & \multirow{3}{*}{33.7} & \multirow{3}{*}{10.5} & 8 & 3.2 & 269.6 \\
\hline & & & 10 & 3.2 & 337 \\
\hline & & & 14 & 3.2 & 471.8 \\
\hline & \multirow{3}{*}{42.2} & \multirow{3}{*}{13.3} & 8 & 3.2 & 339.2 \\
\hline & & & 10 & 3.2 & 424 \\
\hline & & & 14 & 3.2 & 594.6 \\
\hline & \multirow{3}{*}{48.8} & \multirow{3}{*}{15.1} & 8 & 3.2 & 386.4 \\
\hline & & & 10 & 3.2 & 483 \\
\hline & & & 14 & 3.2 & 676.2 \\
\hline \multirow{9}{*}{$\stackrel{゚}{\dot{I}}$} & \multirow{3}{*}{33.7} & \multirow{3}{*}{10.5} & 8 & 3.2 & 269.6 \\
\hline & & & 10 & 3.2 & 337 \\
\hline & & & 14 & 3.2 & 471.8 \\
\hline & \multirow{3}{*}{42.2} & \multirow{3}{*}{13.3} & 8 & 3.2 & 339.2 \\
\hline & & & 10 & 3.2 & 424 \\
\hline & & & 14 & 3.2 & 594.6 \\
\hline & \multirow{3}{*}{48.8} & \multirow{3}{*}{15.1} & 8 & 3.2 & 386.4 \\
\hline & & & 10 & 3.2 & 483 \\
\hline & & & 14 & 3.2 & 676.2 \\
\hline
\end{tabular}

\section{RESULTS OF FINITE ELEMENT MODELS}

\section{USING ANSYS 14.0}

To check the finite element model, a comparisons between the Euro code and analytical results and is carried out. The ultimate loads obtained from the analytical method and finite element analysts (FEA) have been investigated. Table 2 shows comparisons of the ultimate loads of the concrete filled steel tube (CFST) columns obtained analytical and numerically using the finite element model. It can be obtained that good agreements has been obtained b/w two sets of the result for most of the composite columns. 
Table 2:-results of LWC \&SCC both Ansys and Euro code

\begin{tabular}{|c|c|c|c|c|c|}
\hline \multirow{2}{*}{ 党 } & \multirow{2}{*}{ હ } & \multicolumn{2}{|c|}{$\begin{array}{l}\text { ANSYS } \\
\text { LOAD }(\mathrm{KN})\end{array}$} & \multicolumn{2}{|c|}{$\begin{array}{l}\text { EURO CODE } \\
\text { EUC4(KN) }\end{array}$} \\
\hline & & SCC & LWC & SCC & LWC \\
\hline \multirow{18}{*}{ 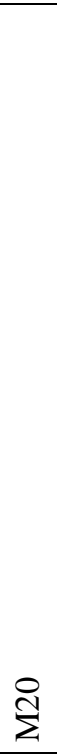 } & 6 & 465.37 & 358.31 & 418.7 & 322.47 \\
\hline & 8 & 264.20 & 203.42 & 234.3 & 180.8 \\
\hline & 10 & 169.0 & 130.13 & 148.7 & 114.4 \\
\hline & 12 & 117.40 & 90.424 & 102.1 & 78.665 \\
\hline & 14 & 79.74 & 61.364 & 68.54 & 52.76 \\
\hline & 16 & 66.30 & 51.232 & 56.3 & 43.54 \\
\hline & 6 & 641.80 & 494.21 & 577.6 & 444.78 \\
\hline & 8 & 363.61 & 279.8 & 323.2 & 249.11 \\
\hline & 10 & 233.51 & 163.40 & 205.4 & 143.6 \\
\hline & 12 & 162.24 & 124.94 & 141.1 & 108.05 \\
\hline & 14 & 118.91 & 91.55 & 103.4 & 79.64 \\
\hline & 16 & 91.41 & 70.41 & 77.6 & 59.85 \\
\hline & 6 & 768.0 & 591.31 & 691 & 532.17 \\
\hline & 8 & 435.0 & 335.1 & 387.1 & 298.15 \\
\hline & 10 & 279.3 & 214.81 & 245.5 & 189.02 \\
\hline & 12 & 191.5 & 147.0 & 166 & 127.89 \\
\hline & 14 & 142.80 & 109.98 & 122 & 94.514 \\
\hline & 16 & 109.51 & 84.388 & 93.0 & 71.655 \\
\hline \multirow{18}{*}{ 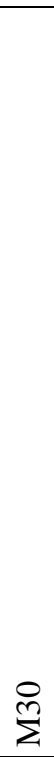 } & 6 & 473.82 & 364.87 & 426.4 & 328.32 \\
\hline & 8 & 269.0 & 207.27 & 239.4 & 231.34 \\
\hline & 10 & 172.41 & 132.17 & 151.3 & 116.24 \\
\hline & 12 & 119.64 & 92.17 & 104.0 & 80.12 \\
\hline & 14 & 88.11 & 67.88 & 75.7 & 58.351 \\
\hline & 16 & 67.52 & 51.95 & 57.3 & 44.19 \\
\hline & 6 & 657.8 & 506.58 & 592.0 & 455.85 \\
\hline & 8 & 372.6 & 286.97 & 331.3 & 255.34 \\
\hline & 10 & 239.11 & 184.17 & 210 & 161.92 \\
\hline & 12 & 166.12 & 127.91 & 144.5 & 111.27 \\
\hline & 14 & 121.8 & 93.77 & 104.7 & 80.58 \\
\hline & 16 & 93.62 & 72.09 & 79.5 & 61.27 \\
\hline & 6 & 790.41 & 608.5 & 711.3 & 547.74 \\
\hline & 8 & 447.01 & 344.55 & 397. & 306.33 \\
\hline & 10 & 287.2 & 221.0 & 252.7 & 194.6 \\
\hline & 12 & 199.8 & 153.87 & 175.8 & 133.8 \\
\hline & 14 & 146.8 & 113.02 & 126.4 & 97.18 \\
\hline & 16 & 112.6 & 86.712 & 95.71 & 73.7 \\
\hline \multirow{18}{*}{$\stackrel{\text { P }}{\sum}$} & 6 & 481.0 & 370.31 & 432.9 & 333.27 \\
\hline & 8 & 273.07 & 210.33 & 242. & 187.16 \\
\hline & 10 & 174.97 & 134.67 & 153.9 & 118.4 \\
\hline & 12 & 121.40 & 93.48 & 105.6 & 81.253 \\
\hline & 14 & 89.51 & 68.76 & 76.9 & 59.058 \\
\hline & 16 & 68.511 & 52.757 & 58.0 & 44.83 \\
\hline & 6 & 671.57 & 516.78 & 604.3 & 465.03 \\
\hline & 8 & 379.98 & 292.57 & 260.3 & 260.32 \\
\hline & 10 & 243.95 & 187.84 & 214.6 & 165.26 \\
\hline & 12 & 169.21 & 130.35 & 147.2 & 113.36 \\
\hline & 14 & 124.24 & 95.663 & 106.8 & 82.26 \\
\hline & 16 & 95.48 & 73.511 & 81.14 & 62.4 \\
\hline & 6 & 809.12 & 622.92 & 728.1 & 560.61 \\
\hline & 8 & 458.11 & 352.81 & 407.7 & 313.99 \\
\hline & 10 & 293.32 & 225.87 & 258.11 & 198.70 \\
\hline & 12 & 204.45 & 157.46 & 177.81 & 136.1 \\
\hline & 14 & 150.28 & 115.71 & 133.62 & 111.0 \\
\hline & 16 & 116.27 & 89.31 & 98.71 & 75.90 \\
\hline
\end{tabular}

\section{COMPARISIONS OF SCC AND LWC FOR} GRADE OF CONCRETE ALONG WITH L/D RATIO

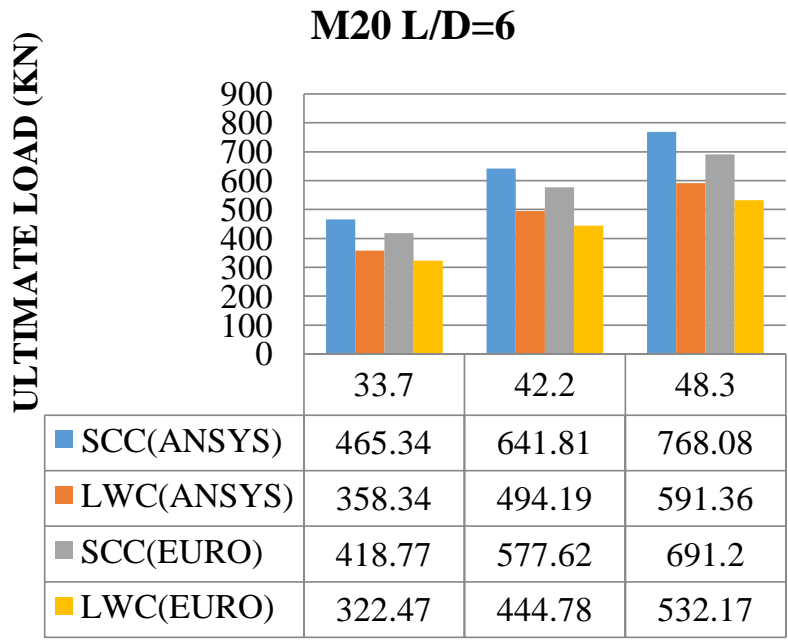

Chart-1 Grade of concrete M20 (1/d=6)

\section{$\mathrm{M} 20 \mathrm{~L} / \mathrm{D}=8$}

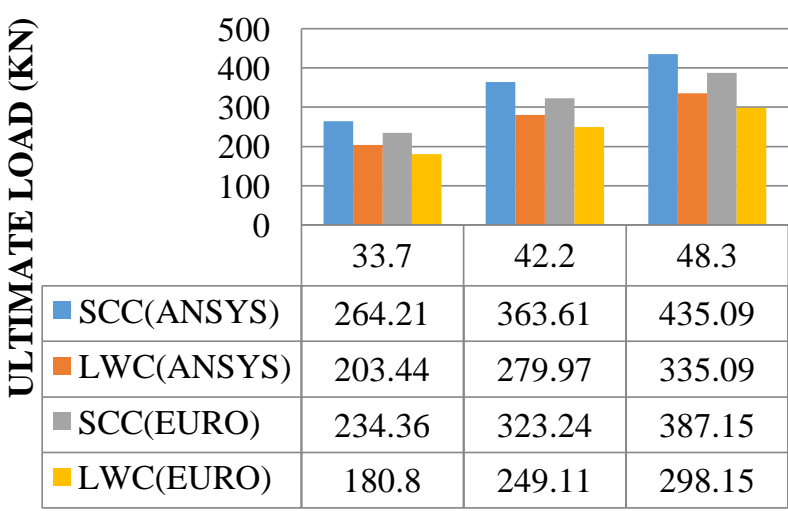

Chart-2: Grade of concrete M20 (1/d=8)

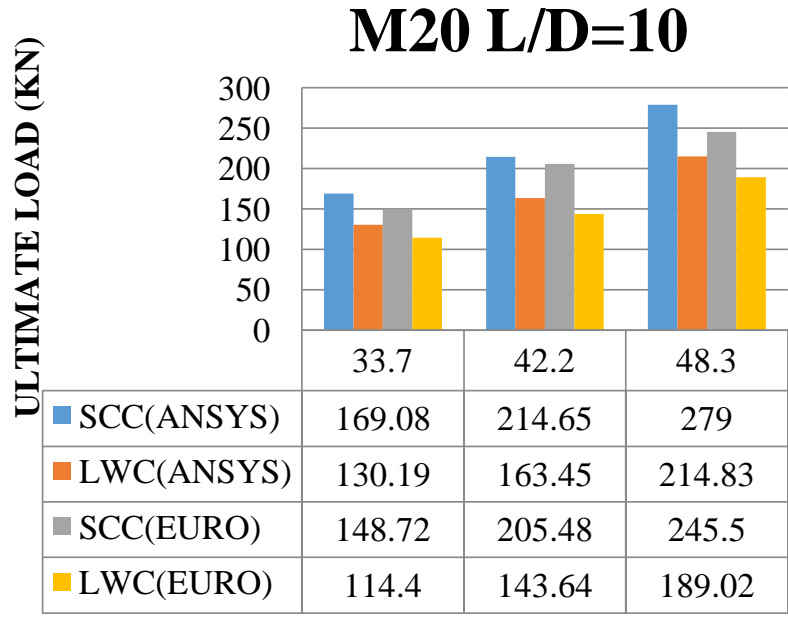

Chart-3 Grade of concrete M20 (1/d=10) 


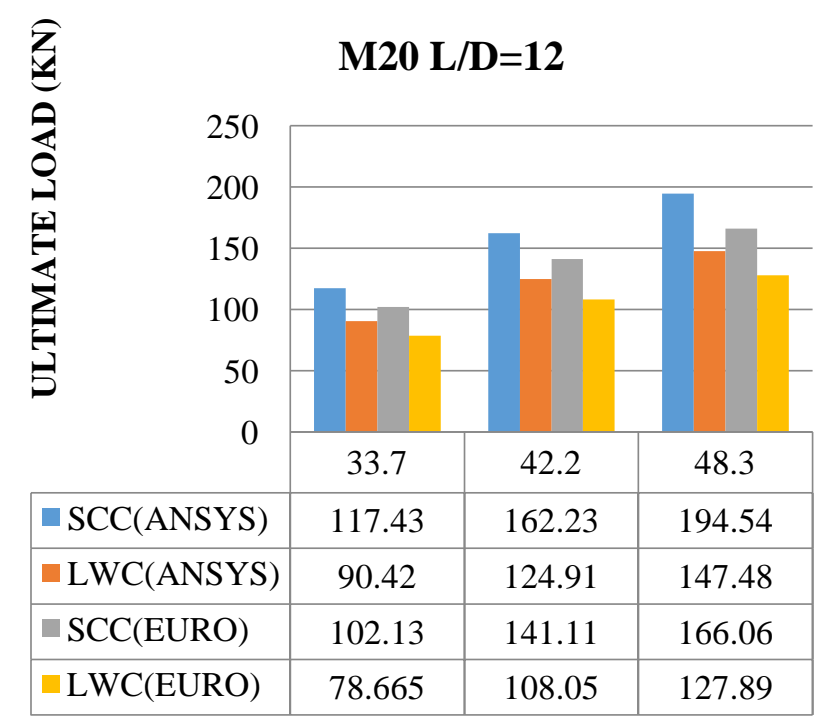

Chart-4: Grade of concrete M20 (1/d=12)

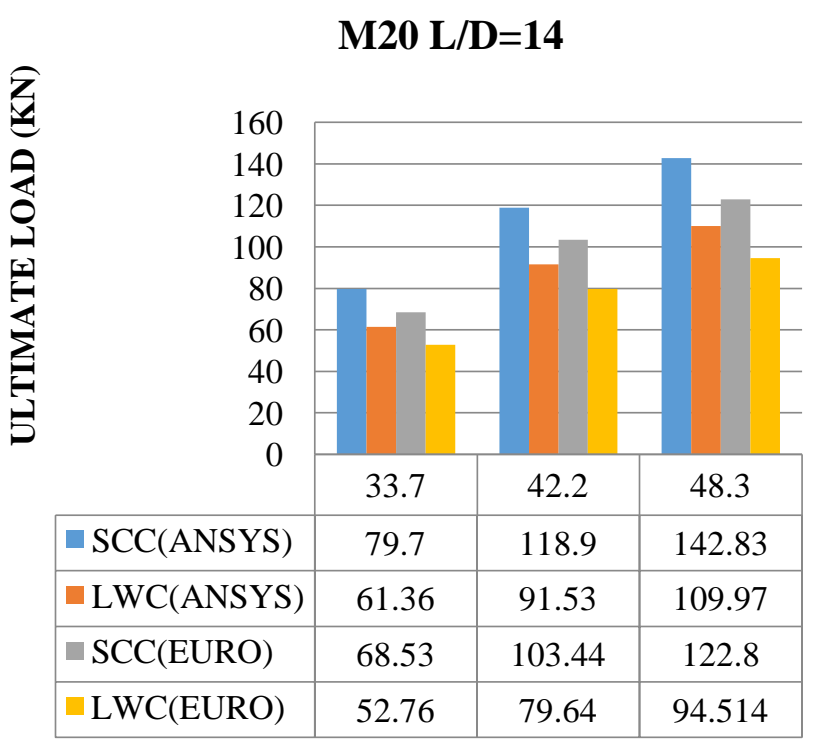

Chart-5: Grade of concrete M20 (1/d=14)

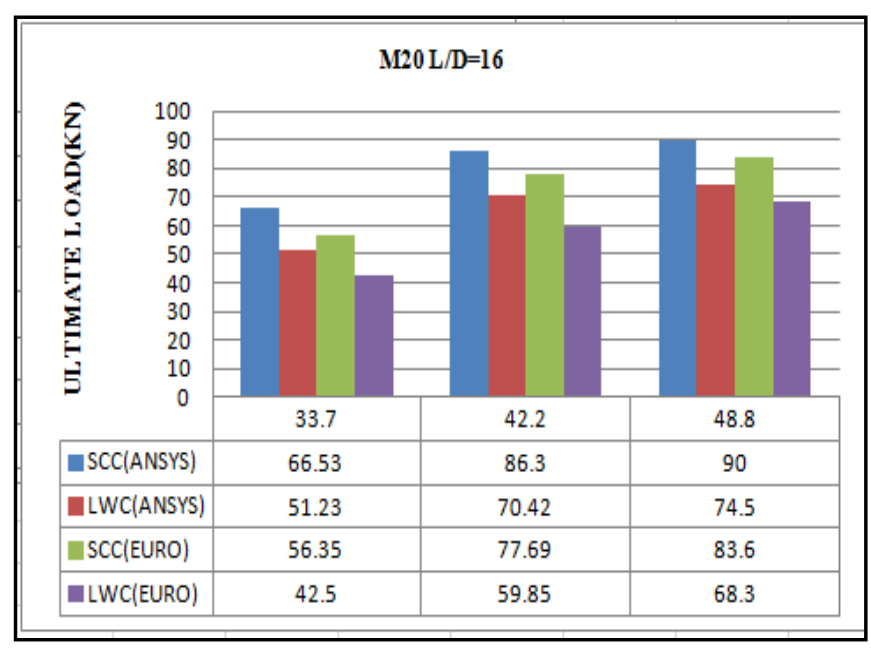

Chart-6 Grade of concrete M20 (1/d=16)
10. RESULTS TABULATED OF HOLLOW COLUMNS

Table 3; - Results of hollow column

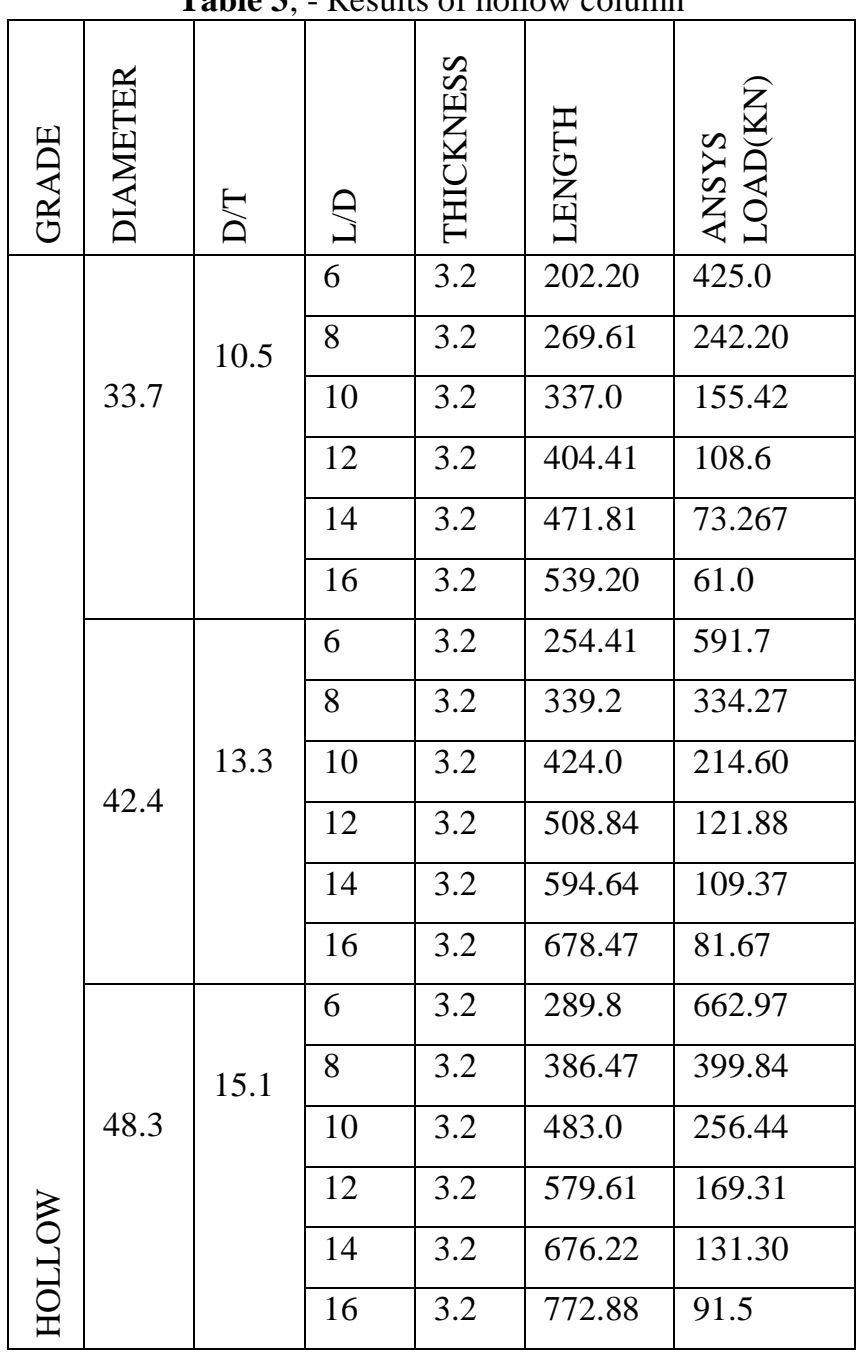

11. COMAPARISON OF HOLLOW STEEL TUBES

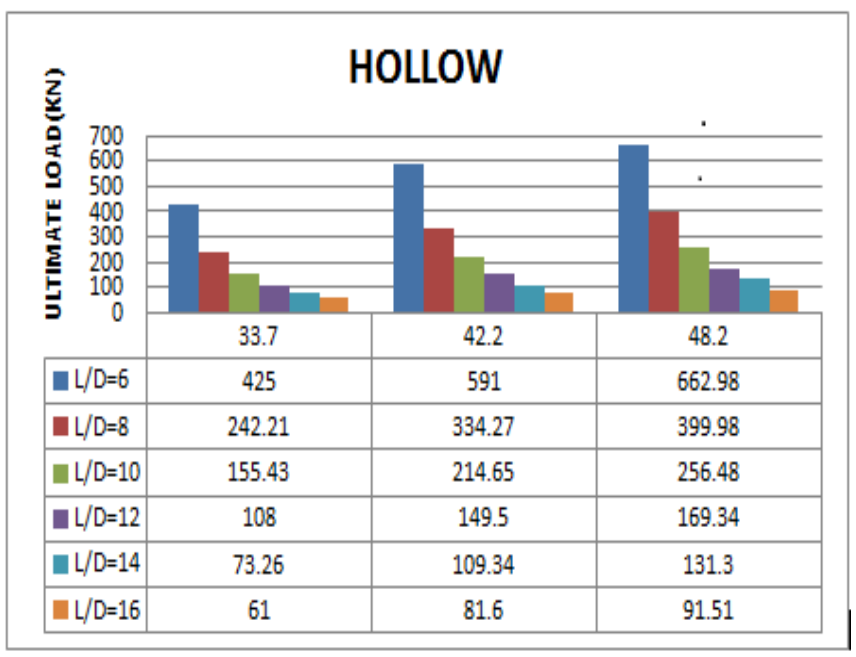

Chart-7: fundamental frequency of hollow steel tube 


\section{GLOBAL BULKING OF COLUMN}

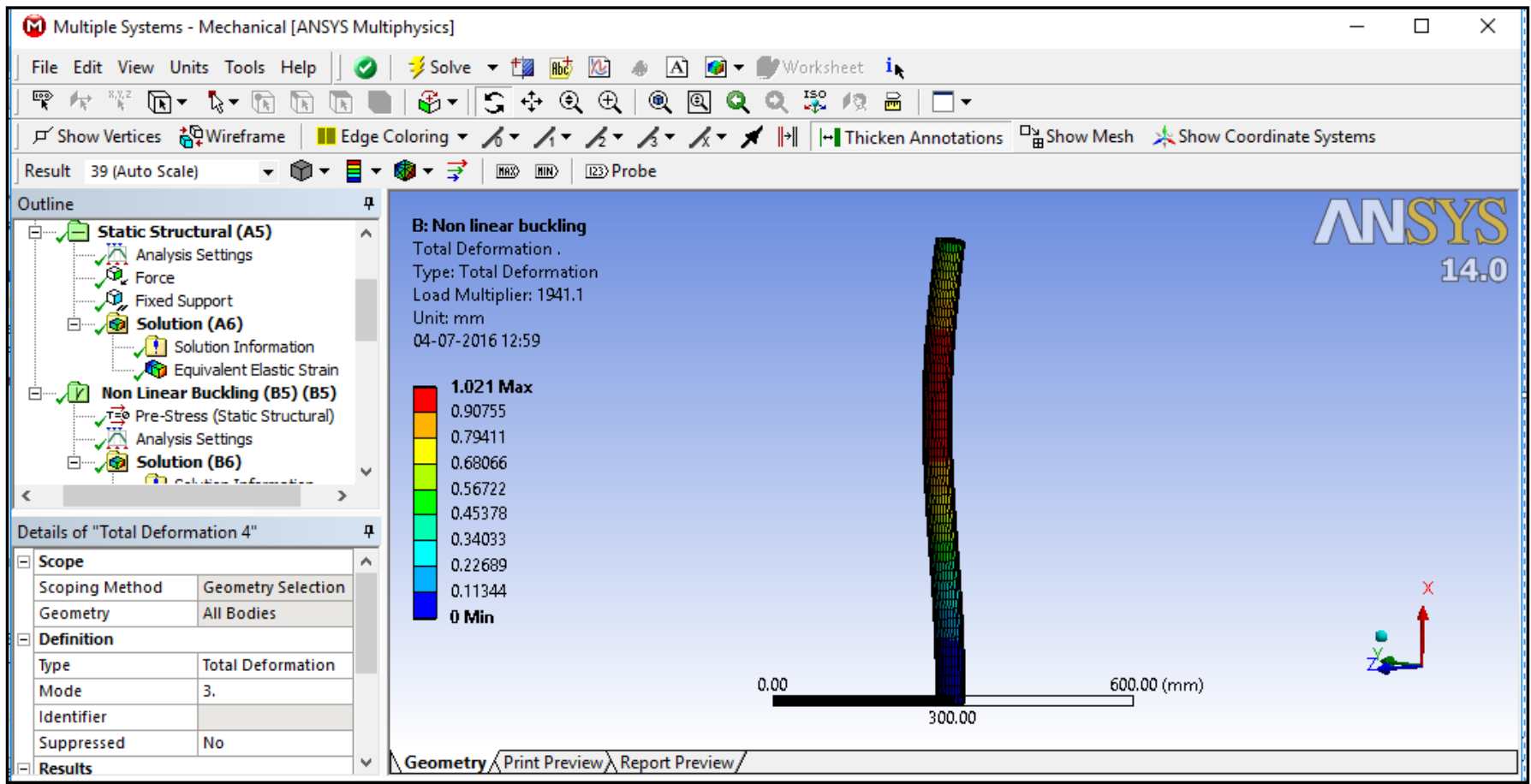

Fig 8 column bulked

\section{CONCLUSION}

"The Light weight concrete is low compressive strength than self compacting concrete, this will be cannot used for the constructions of structural parts or members, such as for a column, beam etc. But this can be effectively used in the constructions of floor slab, partition wall, ventilator, window, etc. The implementation of lieght [LWC] weight concrete more in the structural system lead to more economic. Therefore we can be concluded that".

\section{REFERENCES}

[1]. Schneider SP. "Axial loaded concrete-filled steel tubes' structural engineering ASCE1999; 12(10):1125-38.

[2]. D.S.Ramachandra Murthy"Earthquake resistance of the concrete beam-column joints with TMT \& CRS bars", ICI Journal, vol.II,JulySep.2000,no.2,pp.19-26.

[3]. Elremaily, Aziznamini. Behavior and strength of circular composite concrete-filled tubes columns. Construction steel 2002: 58:1567-91.

[4]. Tao Hong, Wang Dong-yee. Strength and ductility of stiffens thin -walled hollow steel structural columns filled with concrete. Thin Walled structures 2008; 46:1113-28.

[5]. IS 10262.0-1982.0.Indian standard recommendation guidelines for concrete mix designed 